Provided for non-commercial research and education use. Not for reproduction, distribution or commercial use.

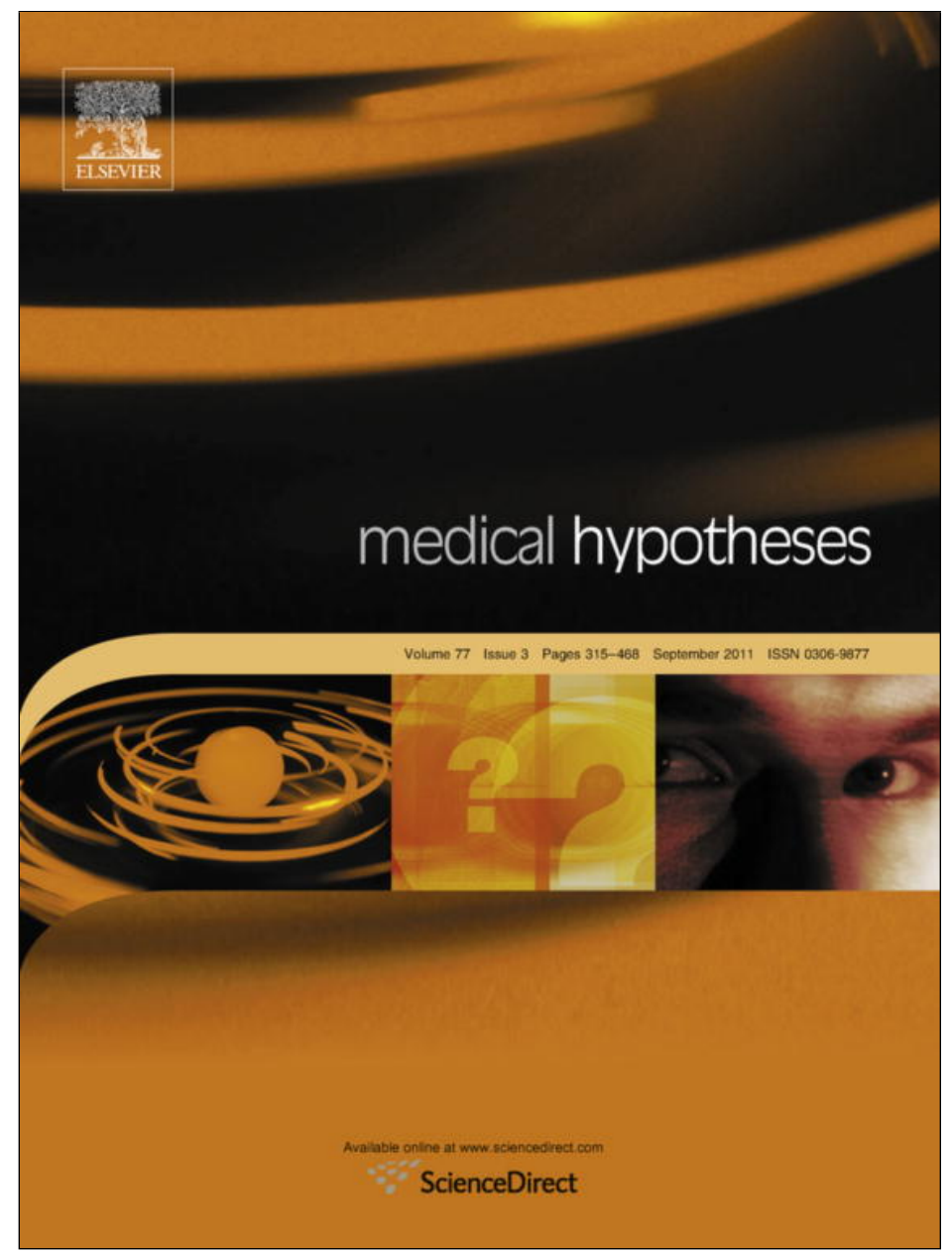

This article appeared in a journal published by Elsevier. The attached copy is furnished to the author for internal non-commercial research and education use, including for instruction at the authors institution and sharing with colleagues.

Other uses, including reproduction and distribution, or selling or licensing copies, or posting to personal, institutional or third party websites are prohibited.

In most cases authors are permitted to post their version of the article (e.g. in Word or Tex form) to their personal website or institutional repository. Authors requiring further information regarding Elsevier's archiving and manuscript policies are encouraged to visit:

http://www.elsevier.com/copyright 


\title{
Obsessive Compulsive Disorder as a functional interhemispheric imbalance at the thalamic level
}

\author{
Óscar F. Gonçalves ${ }^{\mathrm{a}, 1}$, Sandra Carvalho ${ }^{\mathrm{a}, *, 1}$, Jorge Leite ${ }^{\mathrm{a}, 1}$, Fernando Pocinho ${ }^{\mathrm{b}}$, João Relvas ${ }^{\mathrm{b}}$, Felipe Fregni ${ }^{\mathrm{c}}$ \\ ${ }^{a}$ Neuropsychophysiology Laboratory, CIPsi, School of Psychology (EPsi), Campus de Gualtar, University of Minho, 4710-057 Braga, Portugal \\ ${ }^{\mathrm{b}}$ University Hospital of Coimbra, E.P.E, Praceta Prof. Mota Pinto, 3000-075 Coimbra, Portugal \\ ${ }^{\mathrm{c}}$ Neuromodulation Laboratory, Spaulding Rehabilitation Hospital,125 Nashua Street, Boston, MA 02114, Harvard Medical School, United States
}

\section{A R T I C L E I N F O}

\section{Article history:}

Received 10 March 2011

Accepted 7 June 2011

\begin{abstract}
A B S T R A C T
Obsessive Compulsive Disorder (OCD) involves failures in two main inhibitory processes, namely cognitive (obsessions) and behavioral (compulsions). Recent research has supported two cortical-subcortical pathways on OCD pathogenesis: (a) the frontostriatal loop (dorsolateral-caudate-striatum-thalamus) responsible for impairments of behavioral inhibition; (b) the orbitofrontal loop (orbitofrontal, medial prefrontal and cingulate) responsible for impairments with cognitive inhibitory processes. These failures in both cognitive and motor inhibitory systems may mediate several neuropsychological deficits in these patients, namely memory, attention, planning and decision making. But are those deficits related to specific hemispheric effects, namely functional imbalance between hemispheres? In this article we hypothesize that: (1) OCD patients have an inter-hemispheric functional imbalance, probably due to inadequate filtering at the thalamic level; (2) the restoration of inter-hemispheric balance, will be correlative to symptomatic improvement.
\end{abstract}

(c) 2011 Elsevier Ltd. All rights reserved.

\section{Introduction}

Obsessive Compulsive Disorder (OCD) is one of the most debilitating psychiatric disorders. It has a cross cultural lifetime prevalence of $2.5 \%[1,2]$ being characterized by the presence of obsessions (intrusive, upsetting and unwanted thoughts and/or images) and/or compulsions (repetitive and stereotyped behavior or mental rituals) [3].

Most prevailing evidences indicate that OCD is a biological disease. Functional brain imaging studies have converged in order to produce a model for pathophysiology of OCD which involves hyperactivity in certain cortical and subcortical regions [4]. Parallel and partially antagonistic information-processing pathways seem to be involved in order to appropriately create a balanced control of thought and movement. The initiation and sustainability of the repetitive behavior is thought to be modulated by the direct pathway. The completion of these behavioral routines will then be modulated by the indirect pathway. It is suggested that the OCD symptoms result of an hyperactivity in the direct pathway compare to the indirect one leading to a disinhibited thalamus and the creation of a self-perpetuating circuit between the thalamus and the orbital cortex [5,6]. Also, cortico-striatal projections are

\footnotetext{
* Corresponding author. Address: School of Psychology (EPsi), University of Minho, Campus de Gualtar, 4710-057 Braga, Portugal. Tel.: +351 253604220; fax: +351253604224 .

E-mail address: sandrarc@psi.uminho.pt (S. Carvalho).

1 These authors share equal responsibility for the content of this article.
}

predominantly glutamatergic, thus excessive activity may contribute to the pathophysiology of OCD. Successful treatment is associated with a reduction in the CSTC hyperactivity.

Thus, it has been thought that OCD involves failures in two main inhibitory processes, namely cognitive (responsible for the obsessions) and behavioral (responsible for the compulsions) [7]. Recent research has supported two cortical-subcortical pathways in OCD pathogenesis: (a) the frontostriatal loop (dorsolateral-caudate-striatum-thalamus) responsible for impairments of behavioral inhibition; (b) the orbitofrontal loop (orbitofrontal, medial prefrontal and cingulate) responsible for impairments with cognitive inhibitory processes.

These two inhibitory processes reflect a broad network of cortico-basal ganglia-thalamic loops [8,9]. Default mode network (DMN) studies also support this assumption, as OCD patients, when compared to health controls (HC), showed less functional connectivity in anterior cingulate cortex, middle frontal gyrus and putamen [10].

Neurophysiological studies in OCD showed decreased intracortical inhibition (ICI) on paired-pulse TMS (Transcranial Magnetic Stimulation) [11,12] and decreased active and resting motor evoked potential threshold [11] that seems to indicate enhanced cortical excitability and lack of inhibition, when compared to health controls $(\mathrm{HC})$, thus supporting the assumption of failure in inhibition processes.

These failures in both cognitive and motor inhibitory systems [13] may mediate several neuropsychological deficits in these patients, namely memory, attention, planning and decision making 
$[7,14,15]$. But are those deficits related to specific hemispheric effects, namely a functional imbalance between hemispheres?

Several studies suggested specific inter-hemisphere effects. An EEG study [16] demonstrated that OCD patients when compared to HC show less right hemispheric activation. Additionally the beta 2 frequency was correlated with impairments in visuospatial tasks but not with verbal performance. Some authors reported relative decreased variability in the left temporal region [17], "nonspecific theta activity" [18] and a relative significantly increased power in the theta-2 band in the left temporal and central regions along with a significantly reduced variability in frontal and temporal regions [19].

The first TMS study with OCD patients [12], showed symptom improvement when the inhibitory stimulation was on the right dorsolateral prefrontal cortex (DLPFC) but not on the left one. This laterality effect has been also observed in an opposite correlation between acute symptom provocation (as emotional processes play a major role in OCD) and orbitofrontal perfusion in the right and left hemisphere [20], as well as symptom improvement and disruption of abnormal metabolic activity on the right hemisphere after cognitive behavioral therapy [21]. Additionally, symptomatic improvement was found in neurosurgery after right hemisphere anterior capsulotomy but not on left side $[22,23]$. Neuroimaging studies also found right hemisphere changes associated with therapeutic improvement after medication [24]. Also, abnormalities in the thalamus, a sensory and motor gateway to the cortex, are believed to be involved in the pathophysiological mechanisms implicated in the development of OCD symptoms [25,26]. Evidences come from neurosurgery where partial thalamotomy was associated with a decrease in OCD symptoms in treatment-refractory [25] and neuroimaging studies that demonstrate metabolic abnormalities within the thalamus that have been correlated with OCD symptom severity and subsequent treatment response $[5,27,28]$.

All of these studies support the idea that there are specific hemispheric effects associated to both OCD symptoms and cognitive processing, as well as with the prediction of recovery. But none of the above studies clearly demonstrates hemispheric asymmetries and, more important, none of them explore the connectivity in the neural circuitry involved in the pathophysiology.

A possible interpretation for inter-hemispheric imbalance is that the cognitive processing impairments found in OCD may be associated with cortico-basal dysfunction where cortico-subcortical loops (will act separately, in parallel and with overflow between them) [29] will lead to compensatory processes, performed elsewhere in the brain.

Following this hypothesis Gonçalves et al. [30] proposed that the frontal subcortical activation found in OCD would be correlative to a deactivation of parietal/occipital areas associated with visual-perceptual processing, thus supporting the compensatory mechanism hypothesis. This seem to consistent with the hypothesis that in OCD there will be a dysfunction of thalamic gating [31] responsible for a defective filtering of cortical input by the basal ganglia, therefore leading to compensatory processes.

Evidence for the hypothesis of a compensatory activation and deactivation, that will be ultimately responsible for a functional hemispheric imbalance has been found on several clinical trials with repetitive TMS (rTMS), demonstrating increased symptom improvement e.g. [32,33] when compared with alternative approaches [34,35]. In a recent study [36], with 21 medication-resistant OCD patients receiving $1-\mathrm{Hz}$ rTMS (inhibitory stimulation), delivered bilaterally to the Supplementary Motor Area (SMA) it was found a symptomatic improvement along with normalized cortical hyperexcitability (tendency to symmetry between hemispheres).

Nonetheless, due to the unspecific nature of the compensatory mechanisms, the heterogeneity of OCD patients, and the particular characteristics of the cortical-basal-ganglia-thalamic loops, the deficits in these patients seem not to be related to a specific lateralized dysfunction of a particular hemisphere, but probably due to a functional inter-hemisphere imbalance [37]. In other words, there are no data consistently showing that one hemisphere is significantly altered in OCD, but there is data that supports the notion that there is a functional imbalance between them, probably due to inadequate filtering at the thalamic level $[31,38]$.

Previous studies in our lab [39] show that it may be possible to modulate cortically the cortical-basal ganglia-thalamic circuits with cortical transcranial direct current stimulation (tDCS), as these circuits seem to be highly engaged. Our studies seem also to provide evidence that despite of site of stimulation, similar neuromodulation effects could be obtained, as long as the target areas of stimulation are involved in such networks. Also there are several studies that show that it is possible to neuromodulate one hemisphere, by stimulating the other e.g. [40,41], bringing additional support to the idea that as long as the areas are engaged in similar networks, there will be effects in the entire network.

\section{The hypothesis}

The main assumption underlying this hypothesis is that $\mathrm{OCD}$ symptoms and deficits are associated with a functional interhemispheric imbalance. The restoration of such imbalance will be correlative of symptomatic improvement. This assumption could be a possible explanation as why non-invasive standardize rTMS treatments have only revealed modest clinical effects.

In sum, based on previous studies one can hypothesize that:

(1) The activation of positive and negative DMN in OCD will reveal a specific functional hemispheric imbalance and the improvements in symptomatology will be correlative with the restoration of balance.

(2) Quantitative EEG (QEEG), Event-Related-Synchronization (ERS) and Event-Related-Desynchronization (ERD) will show asymmetric distributions, as well as direct cortical excitability measures by single and paired pulse TMS. The restoration of functional connectivity will also be correlative of symptoms improvement.

(3) The cortical site of non-invasive brain stimulation will not be determinant but the main factor will be the bilaterally deliverance in a cortical area highly engaged in the frontal-striatal loops thus targeting changes in the thalamic gating, and ultimately restoration of balance.

\section{Implications and further studies}

If future research validates these hypotheses, important implications may be derived for the development of new therapeutic approaches. For instances, psychotherapy and neurofeedback techniques could be used, in order to promote functional balance between hemispheres. Psychopharmacological treatments could be developed in order to surpass this interhemispheric imbalance by the balance of glutamate and dopamine at the thalamic level. Finally, more recent methods, such as transcranial magnetic stimulation or transcranial direct current stimulation, can be used to bilaterally activate and deactivate several cortical areas related to frontal-subcortical circuits while the patient is confronted with emotional triggers.

\section{Conflicts of interest statement}

There are not any financial, relationship and organizational conflict of interests that may bias any of the authors in the establishment of the hypotheses discussed in this article. 


\section{References}

[1] Stein DJ. Obsessive-compulsive disorder. The Lancet 2002;360:397-405.

[2] Ruscio A, Stein D, Chiu W, Kessler R. The epidemiology of obsessivecompulsive disorder in the National Comorbidity Survey Replication. Mol Psychiatry 2008;15:53-63.

[3] Association AP. Diagnostic and statistical manual of mental disorders. 4th ed. Washington, DC: American Psychiatric Association; 1994.

[4] Saxena S, Rauch SL. Functional neuroimaging and the neuroanatomy of obsessive-compulsive disorder. Psychiatr Clin North Am 2000;23:563-86.

[5] Baxter JR LR. Neuroimaging studies of obsessive compulsive disorder. Psychiatr Clin North Am 1992;15:871-84.

[6] Baxter LR, Saxena S, Brody AL, et al. Brain mediation of Obsessive-Compulsive Disorder symptoms: evidence from functional brain imaging studies in the human and nonhuman primate. Semin Clin Neuropsychiatry 1996:32-47.

[7] Chamberlain S, Blackwell A, Fineberg N, Robbins T, Sahakian B. The neuropsychology of obsessive compulsive disorder: the importance of failures in cognitive and behavioural inhibition as candidate endophenotypic markers. Neurosci Biobehav Rev 2005;29:399-419.

[8] Friedlander L, Desrocher M. Neuroimaging studies of obsessive-compulsive disorder in adults and children. Clin Psychol Rev 2006;26:32-49.

[9] Aouizerate B, Guehl D, Cuny E, et al. Pathophysiology of obsessive-compulsive disorder: a necessary link between phenomenology, neuropsychology, imagery and physiology. Prog Neurobiol 2004;72:195-221.

[10] Jang JH, Kim JH, Jung WH, et al. Functional connectivity in fronto-subcortical circuitry during the resting state in obsessive-compulsive disorder. Neurosci Lett 2010;474:158-62.

[11] Greenberg BD, Ziemann U, Cora-Locatelli G, et al. Altered cortical excitability in obsessive-compulsive disorder. Neurology 2000;54:142.

[12] Greenberg BD, George MS, Martin JD, et al. Effect of prefrontal repetitive transcranial magnetic stimulation in obsessive-compulsive disorder: a preliminary study. Am J Psychiatry 1997;154:867.

[13] Bannon S, Gonsalvez CJ, Croft RJ, Boyce PM. Response inhibition deficits in obsessive-compulsive disorder. Psychiatry Res 2002;110:165-74.

[14] Rao NP, Reddy Y, Kumar KJ, Kandavel T, Chandrashekar C. Are neuropsychological deficits trait markers in OCD? Progr Neuropsychopharmacol Biol Psychiatry 2008;32:1574-9.

[15] Shin MS, Choi H, Kim H, Hwang JW, Kim BN, Cho SC. A study of neuropsychological deficit in children with obsessive-compulsive disorder. Eur Psychiatry 2008;23:512-20.

[16] Kuskowski MA, Malone SM, Kim SW, Dysken MW, Okaya AJ, Christensen KJ. Quantitative EEG in obsessive-compulsive disorder. Biol Psychiatry 1993;33: 423-30.

[17] Flor-Henry P, Yeudall LT, Koles ZJ, Howarth BG. Neuropsychological and power spectral EEG investigations of the obsessive-compulsive syndrome. Biol Psychiatry 1979;14:119-30.

[18] Insel TR, Donnelly EF, Lalakea ML, Alterman IS, Murphy DL. Neurological and neuropsychological studies of patients with obsessive-compulsive disorder. Biol Psychiatry 1983;18:741-51.

[19] Perros P, Young ES, Ritson JJ, Price GW, Mann P. Power spectral EEG analysis and EEG variability in obsessive-compulsive disorder. Brain Topogr 1992;4: 187-92.

[20] Rauch SL, Jenike MA, Alpert NM, et al. Regional cerebral blood flow measured during symptom provocation in Obsessive-Compulsive Disorder using oxygen 15-labeled carbon dioxide and positron emission tomography. Arch Gen Psychiatry 1994;51:62.

[21] Schwartz JM, Stoessel PW, Baxter Jr LR, Martin KM, Phelps ME. Systematic changes in cerebral glucose metabolic rate after successful behavior modification treatment of obsessive-compulsive disorder. Arch Gen Psychiatry 1996;53:109.

[22] Lippitz BE, Mindus P, Meyerson BA, Kihlström L, Lindquist C. Lesion topography and outcome after thermocapsulotomy or gamma knife capsulotomy for obsessive-compulsive disorder: relevance of the right hemisphere. Neurosurgery 1999;44:452.
[23] Lippitz B, Mindus P, Meyerson B, Kihlström L, Lindquist C. Obsessive compulsive disorder and the right hemisphere: topographic analysis of lesions after anterior capsulotomy performed with thermocoagulation. Acta Neurochir Suppl 1997;68:61.

[24] Saxena S, Brody AL, Ho ML, Zohrabi N, Maidment KM, Baxter Jr LR. Differential brain metabolic predictors of response to paroxetine in obsessive-compulsive disorder versus major depression. Am J Psychiatry 2003;160:522.

[25] Modell JG, Mountz JM, Curtis GC, Greden JF. Neurophysiologic dysfunction in basal ganglia/limbic striatal and thalamocortical circuits as a pathogenetic mechanism of obsessive-compulsive disorder. J Neuropsychiatry Clin Neurosci 1989;1:27-36.

[26] Insel TR. Toward a neuroanatomy of obsessive-compulsive disorder. Arch Gen Psychiatry 1992;49:739-44.

[27] Lucey JV, Costa DC, Blanes T, et al. Regional cerebral blood flow in obsessiveompulsive disordered patients at rest. Differential correlates with obsessivecompulsive and anxious-avoidant dimensions. $\mathrm{Br} \mathrm{J}$ Psychiatry 1995;167:629-34.

[28] Cottraux J, Gerard D, Cinotti L, et al. A controlled positron emission tomography study of obsessive and neutral auditory stimulation in obsessive-compulsive disorder with checking rituals. Psychiatry Res 1996;60:101-12.

[29] Haber SN, Calzavara R. The cortico-basal ganglia integrative network: the role of the thalamus. Brain Res Bull 2009;78:69-74.

[30] Gonçalves ÓF, Marques TR, Lori NF, Sampaio A, Branco MC. Obsessivecompulsive disorder as a visual processing impairment. Med Hypotheses 2010;74:107-9.

[31] Rossi S, Bartalini S, Ulivelli M, et al. Hypofunctioning of sensory gating mechanisms in patients with obsessive-compulsive disorder. Biol Psychiatry 2005;57:16-20.

[32] Mantovani A, Simpson H, Fallon B, Rossi S, Lisanby S. Randomized sham controlled trial of low frequency repetitive Transcranial Magnetic Stimulation (rTMS) to the Supplementary Motor Area (SMA) for treatment resistant Obsessive-Compulsive Disorder (OCD). Brain Stimul 2008;1:285.

[33] Mantovani A, Lisanby SH, Pieraccini F, Ulivelli M, Castrogiovanni P, Rossi S. Repetitive transcranial magnetic stimulation (rTMS) in the treatment of obsessive-compulsive disorder (OCD) and Tourette's syndrome (TS). Int J Neuropsychopharmacol 2006;9:95-100.

[34] Alonso P, Pujol J, Cardoner N, et al. Right prefrontal repetitive transcranial magnetic stimulation in obsessive-compulsive disorder: a double-blind, placebo-controlled study. Am J Psychiatry 2001:158:1143.

[35] Sachdev PS, Loo CK, Mitchell PB, McFarquhar TF, Malhi GS. Repetitive transcranial magnetic stimulation for the treatment of obsessive compulsive disorder: a double-blind controlled investigation. Psychol Med 2007;37:1645-9.

[36] Mantovani A, Simpson HB, Fallon BA, Rossi S, Lisanby SH. Randomized shamcontrolled trial of repetitive transcranial magnetic stimulation in treatmentresistant obsessive-compulsive disorder. Int J Neuropsychopharmacol 2010;13:217-27.

[37] Mataix-Cols D, Junqué C, Vallejo JS, Nchez-Turet M, Verger K, Barrios M. Hemispheric functional imbalance in a sub-clinical obsessive-compulsive sample assessed by the Continuous Performance Test, Identical Pairs Version. Psychiatry Res 1997;72:115-26.

[38] Saxena S, Gorbis E, O'Neill J, et al. Rapid effects of brief intensive cognitivebehavioral therapy on brain glucose metabolism in obsessive-compulsive disorder. Mol Psychiatry 2008;14:197-205.

[39] Leite J, Carvalho S, Fregni F, Gonçalves OF. Task specific effects of tDCS-induced cortical excitability changes on cognitive and motor sequence set shifting performance. Submitted for publication.

[40] Mansur C, Fregni F, Boggio P, et al. A sham stimulation-controlled trial of rTMS of the unaffected hemisphere in stroke patients. Neurology 2005;64: 1802.

[41] Fregni F, Boggio PS, Mansur CG, et al. Transcranial direct current stimulation of the unaffected hemisphere in stroke patients. Neuroreport 2005;16:1551. 